\title{
A risk assessment score predicted which elderly patients would fall during a hospital stay
}

Oliver D, Britton M, Seed P, et al. Development and evaluation of evidence based risk assessment tool (STRATIFY) to predict which elderly inpatients will fall: case-control and cohort studies. BMJ 1997 Oct 25;315:1049-53.

\section{Question}

Can a risk assessment tool that uses information on risk factors easily collected by nurses in routine care predict which elderly hospital patients will fall?

\section{Design}

A case control study to develop the tool and 2 cohort studies to validate it.

\section{Settings}

4 wards for elderly patients in a teaching hospital (development and local validation) and 2 acute and 4 rehabilitation wards of a general hospital (remote validation) in the UK.

\section{Patients}

For development of the tool, 116 patients (mean age 85 y) who had fallen (an incident in which a patient suddenly and involuntarily came to rest on the ground or surface lower than their original station) were matched with the patient in the next bed who had not fallen. Local validation was done with 217 patients (395 assessments and 71 falls) and remote validation was done with 331 patients (446 assessments and 79 falls). Mean age was 83 years in both validation groups.

\section{Design of prediction guide}

For each case and control patient, data for 21 variables were collected (including age, sex, function [eg the Barthel Index and transfer and mobility assessment], mental status, use of walking aids, in situ catheter or drip, medication use, medical history, recent history of falls, and nursing assessment of current clinical characteristics). Assessors were not blinded to fall status of the patients. 7 clinical features were associated with falling and 5 factors (presented with fall or has fallen since admission, agitation, major visual impairment, frequent urination needs, and poor transfer and mobility) were used for scale development. For validation each patient was assessed weekly using a scale with scores from $0-5$ for $\leqslant 8$ weeks (each clinical factor was given a score of 1 for yes and 0 for no). Risk scores were compared for those who had and had not fallen for a given week.

\section{Main outcome measures}

Sensitivity and specificity of scores for predicting falls in the local and remote validation studies.

\section{Main results}

A score of $\geqslant 2$ had high sensitivity and a score of $\geqslant 3$ had high specificity for predicting elderly hospital patients who were at risk for falling (table).

\section{Conclusion}

A risk score that predicted which elderly hospital patients were at risk of falling was developed, validated, and found to be accurate.

Validation of a 0 to 5 point risk assessment score to predict which elderly patients were at risk of falling in the hospital

\begin{tabular}{llllrl}
\hline Validation & Score & Sensitivity $(95 \%$ CI) & Specificity $(C I)$ & $+L R^{*}$ & $-L R^{*}$ \\
\hline Local & $\geqslant 2$ & $93 \%(84 \%$ to $98 \%)$ & $88 \%(84 \%$ to $91 \%)$ & 7.6 & 0.08 \\
Local & $\geqslant 3$ & $69 \%(57 \%$ to $80 \%)$ & $96 \%(94 \%$ to $98 \%)$ & 18.6 & 0.3 \\
Remote & $\geqslant 2$ & $92 \%(84 \%$ to $97 \%)$ & $68 \%(63 \%$ to $73 \%)$ & 2.9 & 0.1 \\
Remote & $\geqslant 3$ & $54 \%(43 \%$ to $66 \%)$ & $88 \%(84 \%$ to $91 \%)$ & 4.4 & 0.5 \\
\hline
\end{tabular}

$*+\mathrm{LR}=$ likelihood ratio for falls if the test is positive; $-\mathrm{LR}=$ likelihood ratio if the test is negative. Both calculated from data in article.

Source of funding: no external funding.

For article reprint:Dr D Oliver, Department of Elderly Care (Division of Medicine), United Medical and Dental Schools, St Thomas's Hospital, London SE1 7EH, UK. Fax +44 (0)171 9282339.

A modified version of this abstract appears in ACP Journal Club 1998 May-Jun and Evidence-Based Medicine 1998 May-Jun.

\section{Commentary}

The study by Oliver et al addresses a priority area of health care of elders in the UK. ${ }^{1}$ The authors acknowledge that risk factors associated with falls are complex and may be situation specific. As with the development of risk assessment tools for pressure sores, the key issues arising from the research methodology are related to the selection and weighting of risk factors and the sensitivity and specificity of the tool.

By selecting an unweighted scoring system, the authors have developed a tool that is simple to use, but inevitably is less accurate than a more complex, weighted scoring system might be. They have none the less shown a high level of sensitivity with local use of the tool (ie, it predicted
$93 \%$ of those who fell). When tested at a different site, the tool performed equally well in predicting those who fell, but was less specific - that is, it also predicted that $32 \%$ of those who did not fall would fall. This has implications for cost effective targeting of preventative measures.

The tool might be applicable to hospital settings such as acute and rehabilitation services for older people and orthopaedic services. The remote validation findings of the study indicate that inter-rater reliability (ie, agreement between 2 nurses scoring the same patient) should be checked before the tool is adopted for use. This is because the scoring system incorporates clinical judgment on the part of the nurse, such as assessment of level of agitation. Further implications for application to nursing practice are that the tool has not been validated with a community based sample and therefore cannot be generalised beyond a hospital population.

$$
\begin{array}{r}
\text { Nicky Hayes, RGN, MSc } \\
\text { Senior Lecturer } \\
\text { School of Health, Biological and } \\
\text { Environmental Sciences } \\
\text { Middlesex University } \\
\text { London, UK }
\end{array}
$$

1 Royal College of Physicians and British Geriatrics Society. High quality long term care for elderly people. Guidelines and audit measures. London: RCP, 1992 